\title{
Upaya Meningkatkan Nasabah Tabungan Melalui Tabungan Bajapuik Pada PT. Bank Perkreditan Rakyat (BPR) Batang Kapas
}

\author{
Pimpi Saudatul Rahma, Muhammad Hendra, Nazaruddin Aziz \\ Akademi Keuangan dan Perbankan "Pembangunan" AKBP Padang \\ Sekolah Tinggi Ilmu Ekonomi KBP \\ pimpisaudatulrahma@gmail.com \\ hendraentrepreneurmulia94@gmail.com
}

\begin{abstract}
The purpose of this research is to find out how to increase saving costumers through bajapuik savings in PT. Bank Perkreditan Rakyat (BPR) Batang Kapas. This study uses a descriptive method of how to increase savings costumers through bajapuik savings in PT. BPR Batang Kapas. The results of this study indicate that efforts made by PT. BPR Batang Kapas is improving services in the form of facilities and ifrastructure, carrying out promotions such as distributing brochures to prospective costumers and maintaining customer loyalty.
\end{abstract}

Keywords: Efforts to increase customers.

\section{PENDAHULUAN}

Menurut UU No. 10 Tahun 1998 Tentang perubahan atas UU No. 7 Tahun 1992 tentang perbankan pasal 1 (2): "Bank adalah badan usaha bertugas menghimpun dana dari masyarakat dalam bentuk simpanan serta menyalurkan kembali dalam bentuk kredit dan atau bentuk-bentuk lainnya untuk meningkatkan taraf hidup rakyat banyak (lastri oktavia, 2019).

Bank berperan sebagai lembaga keuangan yang melakukan penghimpun dana dari masyarakat serta menyalurkan kembali dalam bentuk kredit. Bank dapat memberikan bermacam-macam jasa pembiayaan. Bank juga dapat melayani kebutuhan masyarakat dan dunia usaha pengguna jasa kredit untuk meningkatkan kualitas kehidupan masyarakat (Novia, 2018).

Perkembangan bank yang begitu pesat berdampak dari pertumbuhan ekonomi masyarakat sehingga adanya persaingan begitu ketat dalam dunia perbankan. Dari bermacam-macam produk bank yang dikeluarkan dengan fasilitas dan kemudahan untuk menarik minat masyarakat dalam menggunakan jasanya tersebut. Masyarakat ketika ingin menentukan jasa perbankan sesuai kebutuhan, sekarang ini semakin banyak memahami atau fungsi untuk melakukan penyimpanan 
atau melakukan transaksi keuangan sehingga masyarakat akan memilih bank secara lebih selektif.

Perbankan adalah perantara keuangan pihak kelebihan dana dengan kekurangan dana, agar lebih meningkatkan taraf hidup ekonomi masyarakat. Dalam hal ini peranan perbankan sangatlah penting dalam perekonomian sebagai pelajuan sector ekonomi di Indonesia.

Seiring dengan perkembangan perbankan, banyak bank mulai bermunculan, salah satunya Bank Perkreditan Rakyat (BPR). Bank Perkreditan Rakyat yaitu salah satu dari berbagai bank yang kegiatan usaha terbatas dengan transaksi sederhana, meliputi penghimpun dana dari masyarakat dalam bentuk tabungan, deposito berjangka dan penyaluran kredit.

BPR pada saat ini memiliki tugas menghimpun dana dari masyarakat dalam bentuk simpanan,menyalurkan kredit dan menyediakan pembiayaan dana berdasarkan prinsip syariah sesuai ketetapan bank Indonesia dan dananya ditempatkan dalam bentuk sertifikat bank Indonesia (SBI).

Tabungan yaitu bentuk simpanan yang dilakukan antara pihak nasabah dengan bank yang hanya dapat ditarik dengan syarat tertentu (adnan habibulil amri, 2019).

Tabungan bajapuik yaitu layanan yang ada pada PT. Bank Perkreditan Rakyat Batang kapas dengan tujuan memudahkan nasabah untuk menabung, sehingga nasabah tidak perlu lagi pergi ke Bank untuk menabung (adnan habibulil amri, 2019).

Dengan adanya tabungan bajapuik ini pada PT. Bank Perkreditan Rakyat Batang kapas berharap dapat meningkatkan jumlah nasabahnya. tetapi masih ada kendala yang dihadapi oleh pihak Bank BPR yaitu masih kurangnya pengetahuan masyarakat mengenai perbankan dan juga dari calon nasabah sendiri yang memberikan informasi yang tidak benar seperti alamat rumah calon nasabah yang mengakibatkan pihak bank kesulitan mencari alamat rumah calon nasabah dan ketidaktahuan nasabah akan keuntungan menabung di Bank BPR.

\section{Tabel 1}

Jumlah Nasabah Tabungan PT. BPR Batang Kapas 2017-2019

\begin{tabular}{cccc}
\hline Tahun & $\mathbf{2 0 1 7}$ & $\mathbf{2 0 1 8}$ & $\mathbf{2 0 1 9}$ \\
\hline Jumlah Nasabah & 9.422 & 9.765 & 10.298 \\
\hline
\end{tabular}

Sumber : PT. BPR Batang Kapas, 2021

Tabel di atas, menunjukkan peningkatan nasabah jumlah nasabah dari tahun ketahun. Pada tahun 2017-2018 meningkat sebanyak 343 nasabah, dan pada tahun 2018-2019 meningkat 533 nasabah. Peningkatan nasabah paling banyak terjadi pada tahun 2018-2019 yaitu sebanyak 533 nasabah, dan yang paling sedikit tahun 2017-2018 yaitu hanya sebanyak 343 nasabah. 
Peningkatan tersebut terjadi karena upaya yang dilakukan PT. BPR Batang Kapas untuk meningkatkan nasabah. Serta pelayanan tabungan bajapuik yang mendapatkan respon positif dari nasabah yang menabung, karena sebagian besar nasabah merupakan pedagang dan pengusaha UMKM yang kesehariannya sibuk sehingga sangat terbantu dengan adanya tabungan bajapuik ini, dan menimbulkan peningkatan jumlah nasabah tabungan yang lumayan meningkatkan setiap tahunnya. Dan usaha yang dilakukan pihak bank tidak sia-sia juga saling menguntungkan bagi pihak bank juga nasabah.

\section{Metode Penelitian}

\section{Metode Pengumpulan Data}

a. Studi Lapangan (field research)

Yaitu melakukan penelitian langsung untuk mendapatkan data primer. Penelitian langsung kelapangan ini akan dapat membantu penulis untuk melengkapi data yang diperlukan. Adapun cara riset lapangan ini dengan mewawancarai pihak-pihak yang terkait dengan PT. Bank Perkreditan Rakyat Batang Kapas.

b. Studi Kepustakaan (library research)

Yaitu mengumpulkan data dengan cara mempelajari berbagai teori-teori dari literatur dan buku-buku yang berkaitan dengan objek penelitian.

\section{Metode Analisa Data}

Ketika menganalisa sebuah data, penulis menggunakan Metode Analisa data Kualitatif meningkatkan nasabah tabungan pada PT. Bank perkreditan rakyat (BPR) Batang kapas. Metode analisa ditinjau dari dua segi yang berbeda yaitu antara teori dan praktek sehingga dapat diketahui sejauh mana pelaksanaannya, apakah perbedaan yang timbul menyangkut prinsip dasar konsep itu sendiri.

\section{ANALISA DAN PEMBAHASAN \\ Pengertian Bank}

Bagi masyarakat umum masih banyak berpendapat bahwa bank menjadi tempat untuk menyimpan dan meminjam uang. Faktanya bank banyak mempromosikan jasa-jasa lainnya, juga menawarkan jasa simpanan dan pinjaman / kredit. Berbeda dengan orang yang benar paham tentang perbankan dalam menjelaskan pemahaman bank itu sendiri (Nazrian \& Hidayat, 2012).

Bank yaitu jenis lembaga keuangan yang mempunyai peranan sangat penting bagi aktivitas perekonomian. Dalam upaya mencapai tujuan pembangunan yang dilakukan, baik kebijakan fisikal maupun moneter.

Dilihat dari beberapa teri di atas dapat dijelaskan bahwa bank ialah suatu lembaga keuangan, antara pihak kelebihan dana dengan 
kekurangan dana, agar dapat meningkatkan taraf hidup ekonomi masyarakat (ryan pratama putra, 2013).

\section{Fungsi Bank}

Bank sebuah lembaga keuangan tentu memiliki fungsi seperti halnya lembaga-lembaga lain. Fungsi bank dalam perekonomian suatu Negara diklasifikasikan sebagai berikut :

a. Fungsi Bank sebagai Agent of Trust.

Yaitu sebagai lembaga yang pada dasarnya diberikan kepercayaan oleh masyarakat dalam mengamankan dana yang disimpan di bank tersebut.

b. Fungsi Bank sebagai Agent of Development

Yaitu lembaga yang mengumpulkan dana untuk mewujudkan pembangunan dan kesejahteraan dalam perekonomia, karena bank dianggap sebagai lemabaga yang cukup berperan signifikan. Ini desebabkan karena aktifitas bank sebagai financial intermediary (perantara keuangan) yang dapat mempertemukan sektor riil dengan sektor moneter untuk berinteraksi. Sebagian besar peredaran uang dalam perekonomian itu terjadi melalui institusi pada perbankan sehingga diharapkan sektor riil dengan sektor moneter dapat berjalan dengan lancer demi mendukung proses pembangunan.

c. Fungsi Bank sebagai Agent of Service

Lembaga yang memberikan jasa perbankan yang lain untuk masyarakat (Nazrian \& Hidayat, 2012).

Menurut (lastri oktavia, 2019) Bank - bank disebuah negara bisa dibedakan menjadi beberapa jenis.

a. Bank sentral

Bank yang berfungsi menjaga keutuhan dan kestabilan nilai rupiah terhadap nilai tukar lainnya misalnya emas dan perak.

b. Bank umum

Bank ketika kegiatannya berfungsi menghimpun dana dari masyarakat yang diinvestasikan dalam bentuk penanaman modal kemudian menyalurkan dana diperoleh dalam bentuk jasa bank seperti kredit modal usaha. Kredit usaha, kredit biaya pendidikan dan lain-lain.

c. Bank perkreditan rakyat

Yaitu bank yang kegiatan usahanya terbatas dengan transisi sederhana.

\section{Pengertian BPR}

Bank Perkreditan Rakyat bank yang kegiatan usaha terbatas dengan transaksi sederhana, meliputi pengimpun dana dalam bentuk tabungan, deposito dan penyaluran kredit. Keterbatasan ini diberikan 
oleh BPR terkait dengan tujuan pelayanan utama BPR kepada usaha mikro kecil menengah serta masyarakat kecil (rara riezka hidayati, 2018).

Kedudukan BPR diberikan kepada Bank Desa, Lumbung Desa, Bank Pasar, Bank Pegawai, Lumbung Pitih Nagari (LPN), Lembaga perkreditan Desa (LPD), Badan kredit Desa (BKD), Badan Kredit Kecamatan (BKK), Kredit Usaha Rakyat Kecil (KURK), Lembaga Perkreditan Kecamatan (LPK), Bank karya produksi Desa (BKPD), dan / atau lembaga-lembaga lainnya dipersamakan berdasarkan UU Perbankan Nomor 10 tahun 1998 dengan memenuhi suatu persyaratan tatacara ditetapkan dengan suatu peraturan pemerintah.

Ketetapan itu diterapkan mengingat lembaga-lembaga tersebut sudah berkembang dari lingkungan rakyat Indonesia, serta masih diperlukan oleh masyarakat, maka lembaga dimaksud diakui. Oleh sebab itu, UU Perbankan Nomor 10 tahun 1998 memberikan suatu kejelasan kedudukan kepada lembaga-lembaga yang dimaksud. Agar menjamin kesatuan dan keseragaman suatu pembinaan dan pengawasan, maka persyaratan serta tata cara pemberian status lembaga-lembaga dimaksud ditetapkan diperaturan pemerintah.

a. Tugas Bank Perkreditan Rakyat.

1) Menghimpun dana dari masyarakat dalam bentuk simpanan, tabungan atau bentuk lainnya yang dipersamakan dengan itu.

2) Menyalurkan kredit.

3) Disediakan pembiayaan dana berdasarkan prinsip syariah, sesuai ketetapan bank Indonesia.

4) Dananya ditempatkan dalam bentuk sertifikat Bank Indonesia (SBI), Deposito berjangka, sertifikat deposito, dan/ atau tabungan pada Bank lain.

b. Fungsi Bank Perkreditan Rakyat yaitu :

1) Memberi pengetahuan kepada masyarakat, karena masih banyak masyarakat yang belum mengenal apa fungsi dari bank BPR.

2) Menyalurkan kredit.

3) Adanya pelayanan terhadap masyarakat untuk mengambil tabungan.

4) Dananya ditempatkan dalam bentuk sertifikat Bank Indonesia (SBI) deposito berjangka, sertifikat deposito dan / atau tabungan pada bank lain (adnan habibulil amri, 2019).

\section{Pengertian Tabungan}

Tabungan ialah jenis simpanan yang dilakukan oleh pihak ketiga yang dapat ditarik menurut syarat tertentu (Wahyuni, 2018).

Tabungan (saving deposit) merupakan jenis tabungan yang sangat popular dikalangan masyarakat umum lain dari masyarakat kota maupun desa. Seiring perkembangan zaman, masyarakat saat ini justru 
memelurkan bank sebagai tempat menimpan uangnya.Hal ini disebabkan karena keaamanan uangnya yang dibutuhkan oleh masyarakat (Wahyuni, 2018).

Persyaratan untuk dapat membuka rekening tabungan, masingmasing bank berbeda. Akan tetapi, Biasanya persyaratan sama dengan bank lain yaitu setiap masyarakat yang ingin membuka rekening tabungan, perlu menyerahkan fotocopy identitas, seperti SIM, KTP, paspor dan identitas lainnya. Setiap bank akan memberikan persyaratan tentang setoran awal, minimal, serta saldo minimal yang harus disisakan. Saldo akan digunakan untuk membayar biaya administrasi penutupan tabungan (adnan habibulil amri, 2019).

Tempat pengambilan tabungan dana yang ada disrekening dapat menggunakan beberapa sarana yaitu.

Alat-alat yang sering digunakan sebagai berikut :

a. Buku Tabungan

Salah satu bukti bahwa nasabah tersebut nasabah penabung pada bank.

b. Slip Penarikan

Merupakan formulir untuk menarik sejumlah uang dari rekening tabungannya. Di dalamnya nasabah cukup menulis nama, nomor rekening, jumlah uang, serta tanda tangan nasabah..

c. Kwintasi

Kwintasi juga formulir penarikan dan juga bukti penarikan yang dikeluarkan oleh bank fungsinya sama dengan slip penarikan (adnan habibulil amri, 2019).

\section{Promotion (promosi)}

Promosi yaitu komunikasi yang dilakukan untuk memberi penjelasan supaya calon konsumen tertarik tentang barang dan jasa. Hal tersebut agar menarik perhatian, mendidik mengingatkan, dan meyakinkan calon konsumen (Darmadi, 2013).

\section{Periklanan}

Kegiatan periklanan merupakan setiap bentuk presentasi yang berupa promosi, gagasan, barang atau jasa oleh sponsor yang telah ditentukan (rara riezka hidayati, 2018).

Penggunaan promosi dengan iklan dapat dilakukan dengan berbagai media, seperti lewat :

a. Pemasangan bliboard (papan nama) di jalan-jalan strategis.

b. Pencetakkan brosur disebarkan di setiap cabang atau pusat-pusat perbelanjaan.

c. Pemasangan spanduk dilokasi tertentu yang strategis.

d. Melalui Koran.

e. Melalui Majalah.

f. Melalui Televisi.

g. Melalui Radio. 
h. dan menggunakan media lainnya.

\section{Promosi Penjualan}

Usaha yang dilakukan perusahaan untuk menjajakan produk dipasarkan sedemikian rupa, sehingga konsumen akan mudah melihatnya dan tertarik melihatnya, promosi penjualan merupakan insentif jangka pendek untuk mendorong pembelian atau penjualan dari sebuah produk dan jasa dengan tujuan, sebagai berikut:

a. Menarik pelanggan baru.

b. Memberi hadiah kepada konsumen-konsumen lama.

c. Meningkatkan daya pembelian ulang dari konsumen lama.

d. Supaya konsumen tidak berpindah ke merek lain.

e. Mempopulerkan merek atau meningkatkan loyalitas kepada mereka.

f. Meningkatkan volume penjualan jangka pendek dalam rangka meningkatkan pangsa pasar jangka panjang (rara riezka hidayati, 2018).

\section{PEMBAHASAN}

PT. BPR Batang Kapas yaitu bank yang mempunyai kegiatan usaha secara konvensional dalam kegiatannya menghimpun dana dari masyarakat dalam bentuk simpanan berupa deposito berjangka, tabungan, serta menyalurkannya dalam bentuk kredit/pembiayaan.

BPR tumbuh dan berkembang berpengaruh dalam memacu pertumbuhan ekonomi khususnya usaha kecil kondisi ini wajar karena BPR memang lahir dari masyarakat bawah, sehingga BPR tetap menyatu dengan masyarakat. Keberadaan BPR di Indonesia mampu menunjukkan perannya memberikan jasa pelayanan kepada usaha kecil agar dapat melaksanakan tugas pokok dan mempertahannkan kelangsungan BPR, kepercayaan masyarakat sangat penting.

PT. BPR Batang Kapas sangat peduli dan mendukung program yang diadakan pemerintah dalam hal ini bank Indonesia dalam mensosialisasikan manfaat menabung serta wawasan akan dunia perbankan itu sendiri khusunya BPR.

\section{Kegiatan Usaha}

Kegiatan operasional PT. Bank Perkreditan Rakyat Batang Kapas adalah mengimpun dana dalam bentuk tabungan dan deposito, serta menyalurkan dana dalam bentuk kredit.

Beberapa tabungan pada PT. BPR Batang Kapas antara lain :

a. Tabungan Kami (TAMI)

Yaitu produk tabungan untuk seluruh lapisan masyarakat mulai dari penabung kecil sampai penabung besar dimana rencananya akan dibuat undian berhadiah yang dilaksanakan secara bersama dengan BPR-BPR yang tergabung dalam asosiasi bank perkreditan rakyat. 
b. Tabungan bajapuik

Yaitu jenis tabungan yang pelayanannya bisa dijemput seperti kepasar-pasar, kerumah-rumah dengan menggunakan sepeda motor.

c. Tabungan Puro Nagari

Yaitu produk tabungan untuk seluruh lapisan masyarakat mulai dari penabung kecil dan penabung besar.

Ada beberapa penarikan yang digunakan PT. BPR Batang kapas alat-alat yang digunakan sebagai berikut :

a. Buku Tabungan

Merupakan satu dari beberapa bukti bahwa nasabah tersebut adalah nasabah penabung di bank itu. Setiap nasabah diberikan buku tabungan, berupa mutasi setoran, penarikan, dan saldo atas setiap transaksi yang terjadi, sehingga langsung dapat mengurangi atau menambah saldo dibuku tabungan tersebut.

b. Slip Penarikan

formulir untuk menarik sejumlah uang dari rekening tabungannya, di dalam formulir penarikan nasabah cukup menulis nama, nomor rekening, jumlah uang serta tanda tangan nasabah. Formolir penarikan juga kerap disebut dengan slip penarikan karena biasanya kerap digunakan bersama buku tabungan.

Selain menghimpun dana dari Tabungan PT. BPR Batang Kapas juga menghimpun dana dari deposito berjangka sebagai berikut:

a. Jangka Waktu 1 Bulan.

b. Jangka Waktu 3 Bulan.

c. Jangka Waktu 6 Bulan.

d. Jangka Waktu 12 Bulan.

e. Jangka Waktu 24 Bulan.

Untuk menyalurkan dananya PT. BPR Batang Kapas memberikan kredit, fasilitas kredit yang ada pada PT. BPR Batang Kapas adalah :

a. Kredit Usaha Kami (KUMI)

Untuk keperluan modal kerja, investasi dan pembelian barang modal dan lain-lain dengan sistim angsuran mingguan dan bulanan.

b. Kredit Usaha Kecil Informal (KUKI)

Untuk modal kerja dan investasi dengan angsuran bulanan dan jangka waktu maksimal 5 (lima) tahun.

c. Cicilan uang kepada guru-guru dan PNS yang gajinya dibayarkan melalui PT. BPR Batang Kapas.

d. Kredit cicilan uang untuk para pension.

e. Kredit pengelolaan usaha pertanian, perkebunan dan perternakan (KPUP3) yang dikhususkan untuk usaha pengolahan pertanian, perkebunan dan perternakan diwilayah kerja BPR Batang Kapas. 
f. Kredit usaha praktis bagi pegawai, suami atau istri yang bersangkutan yang mempunyai usaha sampingan.

g. Kredit berbagai guna pinjaman - BPR untuk keperluan modal kerja dan investasi dengan sistim pembayaran rekening Koran dan flat.

h. Kredit dana penguatan modal usaha kecil dan mikro (KDM-UMK) untuk keperluan modal kerja yang bekerja sama dengan Bank Nagari Sumbar.

i. Kredit pemberdayaan ekonomi masyarakat untuk keperluan modal kerja atau investasi bagi nasabah mikro yang baru.

\section{Upaya Meningkatkan Nasabah Tabungan}

Untuk meningkatkan nasabah tabungan, PT. BPR Batang Kapas melakukan berbagai cara di antaranya :

a. Menyebarkan Brosur

PT. BPR Batang kapas menyebarkan brosur kepada calon nasabah yang ingin menabung di PT. BPR Batang Kapas. Supaya calon nasabah mengetahui apa saja produk dan jasa yang ada pada PT. BPR Batang Kapas.

b. Membagikan Kalender

PT. BPR Batang Kapas memberikan kalender kepada nasabah/calon nasabah yang berisikan foto kegiatan PT. BPR Batang Kapas itu sendiri, produk/jasa yang ada pada PT. BPR Batang Kapas.Kalender ini dibagikan sendiri oleh karyawan PT. BPR Batang Kapas kerumah nasabah/calon nasabah.

c. Membagikan Parcel

Pembagian parcel/bingkisan biasanya dibagikan sebelum hari-hari besar kepada nasabah setia PT. BPR Batang Kapas agar tetap setia menjadi nasabah PT. BPR Batang Kapas. Parcel yang dibagikan itu biasanya sembako/makanan ringan yang bermanfaat bagi nasabah.

d. Mengadakan Acara Tahunan

Acara tahunan yang dimaksud adalah acara untuk menyambut ulang tahun PT. BPR Batang Kapas. Acara yang diadakan setiap tahunnya ini akan membagikan hadiah bagi nasabah yang beruntung. Acara tersebut diadakan di kantor pusat PT. BPR Batang Kapas.

Selain itu PT. BPR Batang Kapas juga memberikan pelayanan berupa penjemputan tabungan, untuk meningkatkan jumlah nasabahnya.

\section{Tabungan Bajapuik}

Merupakan layanan yang ada pada PT. Bank Perkreditan Rakyat Batang Kapas dengan tujuan memudahkan nasabah untuk menabung, sehingga nasabah tidak perlu lagi pergi ke bank untuk menabung. Karena kebanyakan nasabah yang ikut dalam tabungan bajapuik ini adalah guru PNS pedagang-pedagang pasar yang tidak mempunyai waktu untuk pergi ke bank. Sehingga dengan adanya layanan tabungan bajapuik ini para nasabah 
sangat merasa terbantu dan ini sangat saling menguntungkan anatara kedua belah pihak. Dari upaya yang dilakukan oleh PT. BPR Batang Kapas ini dari pelayanan bajapuik, terjadi peningkatan jumlah nasabah.

Tabungan bajapuik adalah proses penjemputan tabungan yang dilakukan secara kolektif kealamat/ketempat usaha nasabah itu sendiri. Di jemput atas kemauan nasabah, biasanya setiap hari ataupun seminggu sekali tergantung kepada nasabah itu sendiri. Nasabah harus mengkonfirmasi pada saat pembuatan rekening, mau di jemput dimana dan dijemput sekali berapa hari. Dan calon nasabah harus memberikan alamat yang betul supaya pihak bank tidak kesulitan dalam proses penjemputan. Tabungan yang biasa dijemput adalah Tabungan Kami (TAMI), dan Tabungan Puro Nagari. adanya tabungan bajapuik inilah pihak bank mendapatkan keuntungan dengan naiknya jumlah nasabahnya tiap tahun.

\section{SIMPULAN}

a. Upaya peningkatan nasabah melalui Tabungan pada PT. BPR Batang Kapas adalah mengandalkan pola pemasaran tradisional yaitu dengan menggunakan sistem jemput bola dengan menggunakan layanan Tabungan bajapuik. Tabungan bajapuik yang mendapatkan respon positif dari nasabah membuat tabungan bajapuik menjadi sangat popular di kalangan nasabah karena sangat membantu nasabah dalam menabung.

b. Melakukan promosi dengan cara menyebarkan brosur kepada calon nasabah, dengan tujuan agar nasabah mengetahui produk dan pelayanan yang ada pada PT. BPR Batang Kapas.

c. Memepertahankan loyalitas nasabah, PT. BPR Batang Kapas melakukan kegiatan berupa membagikan percel, dan mengadakan acara tahunan.

d. Kendala yang dihadapi dalam meningkatkan jumlah nasabah tabungan

1) Para calon nasabah kurang mengetahui tentang produk yang ditawarkan oleh PT. BPR Batang Kapas.

2) Diperlukan biaya yang cukup besar dalam memperkenalkan PT. BPR Batang Kapas untuk menarik nasabah.

3) Kurangnya keterbukaan dalam hal ini pegawai PT. BPR Batang Kapas dalam memperkenalkan produk di tengah masyarakat, dan juga kurangnya mental untuk menerima penolakan dari masyarakat.

\section{UCAPAN TERIMAKASIH}

Penulis ucapkan puji syukur atas kehadirat-nya, yang telah melimpahkan rahmat dan karunianya kepada penulis sehingga penulis dapat menyelesaikan artikel ini serta Semua pihak yang tidak dapat penulis sebutkan satu persatu. Akhir kata penulis ucapkan terima kasih, 
Semoga artikel ini dapat bermanfaat dan menambah khasanah ilmu pengetahuan. Amin yaa robbal alamiin.

\section{DAFTAR PUSTAKA}

Adnan Habibulil Amri, Ratna Widayati. (2019). Upaya Meningkatkan Nasabah Tabungan Melalui Tabungan Bajapuik Pada Pt. Bank Perkreditan Rakyat (Bpr) Jorong Kampuang Tangah (Jkt) Pariaman. Africa's Potential For The Ecological Intensification Of Agriculture, 53(9), 1689-1699.

Darmadi, D. (2013). Studi Kasus Pt . Astra Internasional Tbk-Tso Cabang Soetoyo Malang . Jurnal Administrasi Bisnis, 2(1), 21-28.

Lastri Oktavia, Jhon Fernos. (2019). Analisis Laporan Keuangan Berdasarkan Tingkat Rentabilitas Bank Bank Perkreditan Rakyat (Bpr) Batang Kapas. Lastri Oktavia, Jhon Fernos, 4(3), 57-71. Http://Marefateadyan.Nashriyat.Ir/Node/150

Hidayati, R. R., \& Marlius, D. (2018). Aktivitas Promosi Dalam Meningkatkan Dana Pihak Ketiga Pada PT. Bank Perkreditan Rakyat (BPR) Batang Kapas Pesisir Selatan. https://doi.org/10.31227/osf.io/8dgqn

Nazrian, A., \& Hidayat, P. (2012). Studi Tentang Keputusan Nasabah Dalam Menabung Di Bank Sumut Cabang Usu Medan Metode Analytical Hierarchy Process (Ahp). Jurnal Ekonomi Dan Keuangan, 1(1), 14864.

Novia, Ratna Widayati. (2018). Upaya Meningkatkan Minat Nasabah Menabung Pada Pt Bank Perkreditan Rakyat Jorong Kampung Tangah Pariaman. Novia, Ratna Widayati, 7, 1-7.

Ryan Pratama Putra, Lena Farida. (2013). Pengaruh Pelayanan Tabungan Bajapuik Terhadap Kepuasan Nasabah Pt. Bank Perkreditan Rakyat Guguk Mas Makmur Kecamatan Guguk Kabupaten 50 Kota Sumatera Barat. Journal Of Chemical Information And Modeling, 53(9), 16891699.

Wahyuni, I. (2018). Jumlah Sertifikat Bank Indonesia (Studi Kasus Pada Bank BCA) Ika Wahyuni *) Anggun Mega Lestari Abstrak Pendahuluan Latar Belakang Sejak Satu Dasawarsa Mengalami Perkembangan Yang Cukup Pesat , Baik Dari Sisi Volume Usaha, Mobilisasi Dana Masyarakat Ma.95-112. 